\title{
Minute Times Micromole per Milliliter
}

National Cancer Institute

\section{Source}

National Cancer Institute. Minute Times Micromole per Milliliter. NCI Thesaurus. Code C85728.

Minutes times micromoles per milliliter. 